\title{
OPTIMASI KONDISI PEMBUATAN ZIRCONIUM BASIC SULPHATE (ZBS) DARI ZIRCONIUM OXYCHLORIDE (ZOC)
}

\author{
Endang Susiantini \\ Pusat Teknologi Akselerator dan Proses Bahan, Badan Tenaga Nuklir Nasional, Yogyakarta \\ email: endangsusiantini@yahoo.co.id
}

Diterima 29 Agustus 2012, diterima dalam bentuk perbaikan 14 Desember 2012, disetujui 17 Desember 2012

\begin{abstract}
ABSTRAK
OPTIMASI KONDISI PEMBUATAN ZIRCONIUM BASIC SULPHATE (ZBS) DARI ZIRCONIUM OXYCHLORIDE (ZOC). Zirkonium merupakan bahan yang baik untuk dimanfaatkan dalam industri nuklir maupun industri non nuklir. Dalam industri nuklir, zirkonium adalah bahan yang strategis karena mempunyai tampang lintang absorpsi netron rendah. Tujuan penelitian ini adalah untuk mencari kondisi optimum proses pengendapan ZBS agar mendapatkan endapan ZBS yang terbanyak. Metode pembuatan ZBS yaitu dengan menambahkan larutan sulfat dari $\mathrm{H}_{2} \mathrm{SO}_{4}$ ke dalam larutan ZOC, dipanaskan dan diaduk dalam kurun waktu tertentu sampai terbentuk endapan ZBS. Endapan disaring dan dicuci untuk menghilangkan pengotor-pengotor seperti Fe, Ti, U dan Th. Umpan ZOC yang digunakan adalah hasil proses dari peleburan pasir zirkon yang berkadar $72 \mathrm{~g}$ Zr/L ditambah $\mathrm{H}_{2} \mathrm{SO}_{4}$ di dalam refluk yang dilengkapi dengan pengatur suhu sampai reaksi sempurna.. Diperoleh endapan putih ZBS berbentuk slurry, endapan dipisahkan dari filtrat dan disaring, filtrat dianalisis kandungan zirkoniumnya dengan XRF untuk setiap variabel proses. Kondisi optimum proses adalah $\mathrm{pH}=1,3$ konsentrasi umpan $=0,2 \mathrm{M}$ , suhu reaksi $=90^{\circ} \mathrm{C}$ dan waktu pemanasan $=60$ menit dan konversi endapan $Z B S=94,35 \%-96,78 \%$.
\end{abstract}

Kata kunci: Zirconium Basic Sulphate (ZBS), Zirconium Oxychloride (ZOC), XRF

\section{ABSTRACT}

OPTIMIZATION CONDITIONS OF PREPARATION ZIRCONIUM BASIC SULPHATE (ZBS) FROM ZIRCONIUM OXYCHLORIDE (ZOC).). Zirconium is a good material for use in the nuclear industry as well as non-nuclear industries. In the nuclear industry, zirconium is a strategic material because it has a low neutron absorption cross section. The purpose of this study is to find the optimum condition ZBS precipitation process in order to get the most precipitate ZBS. The method preparation of ZBS by adding a solution of $\mathrm{H}_{2} \mathrm{SO} 4$ to zirconium oxyklorid into solution, heated and stirred in a certain period of time until it forms a precipitate ZBS. The precipitate is filtered and washed to remove impurities such as Fe, Ti, $U$ and Th. Zirconium oxychloride (ZOC) used as feed for concentration $\mathrm{Zr} 72 \mathrm{~g} / \mathrm{L}$ is the result of fusion zircon sand process added $\mathrm{H}_{2} \mathrm{SO}_{4}$ in refluxing equipped with temperature control until complete reaction. Zirconium Basic Sulphate (ZBS) a white precipitate slurry form obtained, the precipitate is separated from the filtrate and filtered, filtrate was analyzed by XRF for each variable zirconium content. The optimum process conditions were $\mathrm{pH}=1.3$ feed concentration $=0.2 \mathrm{M}$, the reaction temperature $=90^{\circ} \mathrm{C}$ and heating time $=60 \mathrm{~min}$ and the precipitation conversion of ZBS was $94.35 \%$ to $96.78 \%$.

Keywords: Zirconium Basic Sulphate (ZBS), Zirconium oxychloride (ZOC),

\section{PENDAHULUAN}

7 irkonium adalah unsur kimia dengan simbol $\mathrm{Zr}$, konfigurasi elektron adalah $[\mathrm{Kr}] 4 \mathrm{~d}^{2} 5 \mathrm{~s}^{2}$ dengan nomor atom 40 dan massa atom adalah 91,224. Zirkonium ion dapat bermuatan $+1,+3$ dan yang paling tinggi adalah $\mathrm{Zr}^{+4}$ adalah muatan ion yang mempunyai radius paling besar yaitu $0.86^{\circ} \mathrm{A}$ dan tidak stabil dan larutan garam zirkonium dapat terjadi reaksi hidrolisis, polimerisasi dan hidrasi tergantung kondisinya. Garam zirkonium terdisosiasi di dalam air pada $\mathrm{pH}$ rendah sebagai contoh $\mathrm{Zr}^{+4}$ berikatan dengan ion hidrat dengan 8 molekul air dan di dalam larutan terhidrolisis membebaskan hidronium sebagai berikut: 


$$
\begin{gathered}
{\left[\mathrm{Zr}\left(\mathrm{H}_{2} \mathrm{O}\right) 8\right]+8+\mathrm{HH}_{\mathrm{y}^{2}} \mathrm{O} \rightarrow \underset{\substack{\downarrow\\
}}{ }\left[\mathrm{Zr}\left(\mathrm{H}_{2} \mathrm{O}\right) 7(\mathrm{OH})\right]+3+\mathrm{H}_{3} \mathrm{O}+} \\
{\left[\mathrm{Zr}\left(\mathrm{H}_{2} \mathrm{O}\right) 6(\mathrm{OH})_{2}\right]+2+\mathrm{H}_{2} \mathrm{O}}
\end{gathered}
$$

Ada 2 macam proses untuk mengubah konsentrat zirkonium menjadi bahan jadi yaitu proses basah dan kering. Proses basah yaitu dengan melebur konsentrat zirkonium dengan $\mathrm{NaOH}$ pada suhu $\left(750-900{ }^{\circ} \mathrm{C}\right)$ dilindi dengan air, kemudian dilindi dengan $\mathrm{HCl}$ untuk mendapatkan $\mathrm{ZrOCl}_{2} .8 \mathrm{H}_{2} \mathrm{O}$ dengan reaksi sebagai berikut(1):

$$
\begin{aligned}
& \mathrm{ZrSiO}_{4}+4 \mathrm{NaOH} \mathrm{N} \rightarrow \mathrm{Na}_{2} \mathrm{ZrO}_{3}+\mathrm{Na}_{2} \mathrm{SiO}_{3}+2 \mathrm{H}_{2} \mathrm{O} \\
& \mathrm{Na}_{2} \mathrm{ZrSiO}_{3}+4 \mathrm{HCl} \rightarrow \mathrm{ZrOCl}_{2} 8 \mathrm{H}_{2} \mathrm{O}+\mathrm{SiO}_{2}+\mathrm{NaCl}
\end{aligned}
$$

Proses kering yaitu dengan karboklorinasi konsentrat zirkonium dengan gas $\mathrm{Cl}_{2}$ pada suhu $800-1100{ }^{\circ} \mathrm{C}$ menghasilkan gas $\mathrm{SiCl}_{4}$ dan $\left(\mathrm{ZrCl}_{4}+\mathrm{HfCl}_{4}\right)$. Kedua gas tersebut dipisahkan pada fraksi yang berbeda dan $\left(\mathrm{ZrCl}_{4}+\mathrm{HfCl}_{4}\right)$ dihidrolisis menjadi $\mathrm{Zr} / \mathrm{HfOCl}_{2}$ dengan persamaan reaksi sebagai berikut:

$$
\begin{aligned}
& \mathrm{ZrSiO}_{4}+\mathrm{C}+4 \mathrm{Cl}_{2} \rightarrow \mathrm{ZrCl}_{4}+\mathrm{SiCl}_{4}+4 \mathrm{CO} \\
& \mathrm{ZrCl}_{4}+\mathrm{H}_{2} \mathrm{O} \rightarrow \mathrm{ZrOCl}_{2} .8 \mathrm{H}_{2} \mathrm{O}
\end{aligned}
$$

Struktur $\mathrm{ZrOCl}_{2} .8 \mathrm{H}_{2} \mathrm{O}$ telah ditentukan oleh Clearfied dan Cowokers dengan $\mathrm{X}$-ray adalah kristal tunggal dengan komposisi $\left[\mathrm{Zr}_{4}(\mathrm{OH})_{8}\left(\mathrm{H}_{2} \mathrm{O}\right)_{16}\right]^{+8}$ seperti pada gambar 1.(1-3).

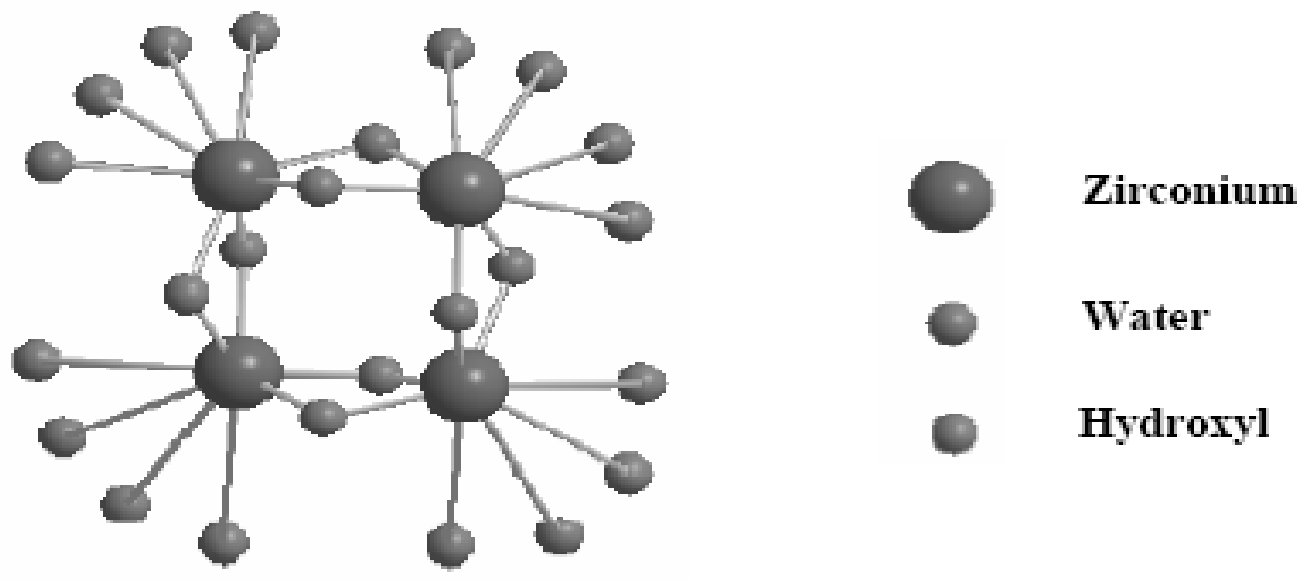

Gambar 1. Struktur dari $\left[\mathrm{Zr}_{4}(\mathrm{OH})_{8}\left(\mathrm{H}_{2} \mathrm{O}\right)_{16}\right]^{+8}$

Kristal $\mathrm{ZrOCl}_{2} .8 \mathrm{H}_{2} \mathrm{O}$ terhidrolisis dalam air sebagai berikut:

$$
4\left[\mathrm{ZrOCl}_{2} .8 \mathrm{H}_{2} \mathrm{O}\right]_{(\mathrm{s})}+\mathrm{H}_{2} \mathrm{O} \stackrel{\mathrm{HCl}}{\leftrightarrow}\left[\mathrm{Zr}_{4}(\mathrm{OH})_{8}\right]^{+8}+8 \mathrm{Cl}^{-}+29 \mathrm{H}_{2} \mathrm{O}
$$

Zirkonium oksiklorid $\mathrm{ZrOCl}_{2} .8 \mathrm{H}_{2} \mathrm{O}$ baik proses kering maupun basah masih mengandung pengotor-pengotor yaitu $\mathrm{Fe}, \mathrm{Ti}, \mathrm{Al}, \mathrm{U}$ dan Th. Pengotor-pengotor tersebut dapat dihilangkan dengan cara penngendapan menjadi Zirconium Basic Sulphate (ZBS)(4). Namun jika tidak melalui jalur ZBS maka dilanjutkan dengan pengendapan menjadi zirkonium hidroksid sebagai berikut(5)

$$
\begin{aligned}
& 2 \mathrm{ZrOCl}_{2} .8 \mathrm{H}_{2} \mathrm{O}+\mathrm{NH}_{4} \mathrm{OH}+\mathrm{H}_{2} \mathrm{O} \rightarrow \mathrm{Zr}(\mathrm{OH})_{4}+2 \mathrm{NH}_{4} \mathrm{Cl} \\
& {\left[\mathrm{Zr}_{4}(\mathrm{OH})_{8}\right]^{+8}+8 \mathrm{Cl}+8 \mathrm{NH}_{4} \mathrm{OH}+\mathrm{H}_{2} \mathrm{O} \rightarrow 4 \mathrm{Zr}(\mathrm{OH})_{4}+8 \mathrm{NH}_{4} \mathrm{Cl}}
\end{aligned}
$$

Zirconium Basic Sulphate (ZBS) adalah merupakan senyawa antara yang merupakan kristal berwarna putih, tidak larut dalam air, tidak berbau, $\mathrm{pH}=3-5$, bulk density $=0,7$ dengan rumus molekul $\mathrm{Zr}_{5} \mathrm{O}_{8}\left(\mathrm{SO}_{4}\right)_{2}$. Metode pembuatan ZBS(6-7), yaitu dengan menambahkan larutan sulfat dapat dari $\mathrm{H}_{2} \mathrm{SO}_{4}$ atau $\left(\mathrm{NH}_{4}\right)_{2} \mathrm{SO}_{4}$ ke dalam larutan zirkonium oxyklorid, dipanaskan dan diaduk dalam kurun waktu tertentu sampai terbentuk endapan ZBS. Endapan disaring dan dicuci untuk menghilangkan pengotor-pengotor seperti Fe, Ti, U dan Th. Reaksi yang terjadi bila digunakan sumber sulfat dari $\mathrm{H}_{2} \mathrm{SO}_{4}$ adalah seperti disajikan pada persamaan (9).

$$
5 \mathrm{ZrOCl}_{2} .8 \mathrm{H}_{2} \mathrm{O}+2 \mathrm{H}_{2} \mathrm{SO}_{4}+10 \mathrm{NH}_{4} \mathrm{OH} \leftrightarrows \mathrm{Zr}_{5} \mathrm{O}_{8}\left(\mathrm{SO}_{4}\right)_{2} .15 \mathrm{H}_{2} \mathrm{O}+10 \mathrm{NH}_{4} \mathrm{Cl}+32 \mathrm{H}_{2} \mathrm{O}
$$


Dari literatur(7-8), kondisi reaksi (9), adalah suhu $=80-90{ }^{\circ} \mathrm{C}, \mathrm{pH}=1,1-1,55, \mathrm{Zr} / \mathrm{SO}_{4}, 5 / 2,\left[\mathrm{ZrOCl}_{2}\right]=0,2 \mathrm{M}$ dan $[\mathrm{HCl}]=1,0 \mathrm{~N}$. Jika sumber sulfat dari $\left(\mathrm{NH}_{4}\right)_{2} \mathrm{SO}_{4}$ maka reaksinya adalah(8):

$$
5 \mathrm{ZrOCl}_{2} .8 \mathrm{H}_{2} \mathrm{O}+2\left(\mathrm{NH}_{4}\right)_{2} \mathrm{SO}_{4}+3 \mathrm{H}_{2} \mathrm{O} \stackrel{\mathrm{NaOH}}{\longrightarrow} \mathrm{Zr}_{5} \mathrm{O}_{8}\left(\mathrm{SO}_{4}\right)_{2} .15 \mathrm{H}_{2} \mathrm{O}+4 \mathrm{NH}_{4} \mathrm{Cl}+25 \mathrm{H}_{2} \mathrm{O}+6 \mathrm{HC}-(10)
$$

Dari literatur(6-8), kondisi reaksi (10), adalah suhu $=80-90{ }^{\circ} \mathrm{C}, \mathrm{pH}=1,8-2,0, \mathrm{Zr} / \mathrm{SO}_{4}=5 / 2$.

Reaksi (9), reaktannya adalah $\mathrm{H}_{2} \mathrm{SO}_{4}$ sehingga untuk membuat $\mathrm{pH}$ sekitar 1,1-1,55 dengan penambahan $\mathrm{NH}_{4} \mathrm{OH}$ yang cukup banyak. Reaksi (10), reaktannya adalah $\left(\mathrm{NH}_{4}\right)_{2} \mathrm{SO}_{4}$ sehingga untuk mencapai pH sekitar 2,0 tidak terlalu banyak membutuhkan reaktan tersebut dan $\left(\mathrm{NH}_{4}\right)_{2} \mathrm{SO}_{4}$ relatif lebih murah daripada $\mathrm{H}_{2} \mathrm{SO}_{4}$. Kegunaan ZBS adalah sebagai bahan cat kering, pelapis kertas dan sebagai starting material untuk senyawa zirkon lainnya ${ }^{(8-9)}$. Ada bermacam-macam spesifikasi produk ZBS dipasaran, sebagai contoh speksifikasi yang dihasilkan dari Cina disajikan pada tabel 1.

Tabel 1. Komposisi spesifikasi ZBS(9-11).

\begin{tabular}{|c|c|c|c|c|c|}
\hline $\mathrm{ZrO}_{2}+\mathrm{HfO}_{2}(\min )$ & $\mathrm{Fe}_{2} \mathrm{O}_{3}(\max )$ & $\mathrm{SiO}_{2}(\max )$ & $\mathrm{Na}_{2} \mathrm{O}(\max )$ & $\mathrm{TiO}_{2}(\max )$ & $\mathrm{SO}_{4}(\max )$ \\
\hline $35-42 \%$ & $0,002 \%$ & $0,01 \%$ & $0,1 \%$ & $0,002 \%$ & $17-19 \%$ \\
\hline
\end{tabular}

Tujuan penelitian ini adalah untuk mendapatkan kondisi optimum proses pembuatan ZBS dengan konversi endapan ZBS yang terbanyak. Zirkonium Basic Sulphate (ZBS) merupakan senyawa antara pada proses pembuatan zirkonia karena dengan menggunakan jalur ZBS tersebut diharapkan dapat mengurangi pengotor-pengotor $\mathrm{Fe}, \mathrm{Ti}$, Th dan U. Selain itu, jalur ZBS ini sangat diperlukan dalam pembuatan umpan pada pemisahan Zr-Hf dengan Countinuous Annular Chromatograhy (CAC)(12). Umpan pada pemisahan $\mathrm{Zr}-\mathrm{Hf}$ dengan $\mathrm{CAC}$ berbentuk spesies $\mathrm{Zr}\left(\mathrm{SO}_{4}\right)_{3}^{-2}$ dengan pengotor sekecil mungkin karena jika terlalu banyak pengotor akan membebani resin penukar anion Dowex 1-X-8.(13-14) Diharapkan pada kondisi tersebut dapat mengurangi atau menghilangkan pengotor $\mathrm{Fe}, \mathrm{Ti}$, Th dan $\mathrm{U}$.

Reaksi kimia terjadi bila terjadi tumbukan antar molekul yang mempunyai energi yang cukup untuk memecah ikatan dalam suatu reaktan. Pada umumnya reaksi kimia dipengaruhi oleh suhu, waktu, konsentrasi dan $\mathrm{pH}$. Kenaikan suhu menyebabkan gerakan molekul lebih cepat sedang kenaikan konsentrasi menyebabkan kebolehjadian bertumbukan menjadi lebih besar sehingga menaikkan kecepatan reaksi(15). Dalam penelitian ini digunakan konsentrasi umpan adalah $0,2 \mathrm{M}$, karena pada konsentrasi tersebut larutan umpan zirconium oxychloride (ZOC) terdissosiasi sempurna menjadi kation yang stabil. Pengaruh $\mathrm{pH}$ pengendapan, literatur (16) menyebutkan jika dalam asam sulfat, uranium mengendap sebagai $\mathrm{UO}_{2} \mathrm{SO}_{4}$ pada $\mathrm{pH}$ kurang lebih 1,03-1,6 sedangkan sebagai $\mathrm{U}\left(\mathrm{SO}_{4}\right)_{2}$ pada $\mathrm{pH} 0,1-1,95$. Thorium mengendap sebagai $\mathrm{Th}\left(\mathrm{SO}_{4}\right)_{4}$ pada $\mathrm{pH}$ sekitar 2,8-5,2 dan $\mathrm{Ti}\left(\mathrm{SO}_{4}\right)_{4}$ pada $\mathrm{pH} 3,55-4$ dan feri/fero sulfat mengendap pada $\mathrm{pH}=8$. Diharapkan dengan menggunakan jalur pengendapan dalam asam sulfat serta pada kondisi optimum proses pengendapan ZBS diperoleh zirkonia yang lebih murni.

\section{METODOLOGI}

\section{Bahan}

Bahan yang digunakan adalah: $\mathrm{ZOC}$ hasil proses, $\mathrm{H}_{2} \mathrm{SO}_{4}$ pekat $97 \%, \mathrm{ZrOCl}_{2} .8 \mathrm{H}_{2} \mathrm{O}$ semua bahan kimia dari MERCK, $\mathrm{NH}_{4} \mathrm{OH}, \mathrm{H}_{2} \mathrm{SO}_{4}$ pekat air bebas mineral (ABM).

\section{Alat}

Alat yang digunakan adalah: Gelas beker, Neraca analitik, Pipet gondok, Pipet volume, Mikro pipet, Labu ukur, Kaca Arloji, pH meter, Pengaduk, Milar, Botol sampel, oven, XRF, seperangkat alat pembuatan ZBS (Gambar.2).

\section{Persiapan umpan}

Ditimbang sejumlah tertentu ZOC hasil proses, dilarutkan dalam ABM diaduk sampai hampir jenuh. Diambil sebanyak $5 \mathrm{ml}$ dianalisis dengan XRF. 


\section{Pembuatan larutan ZBS}

Diambil volume tertentu umpan $\mathrm{ZOC}$, masukkan dalam gelas beker, tambahkan $\mathrm{H}_{2} \mathrm{SO}_{4}$ dengan volume tertentu diaduk dan pHnya ditepatkan dengan menambah $\mathrm{NH}_{4} \mathrm{OH} / \mathrm{HCl}$ sampai $\mathrm{pH}$ yang dikehendaki kemudian volume ditepatkan menjadi $250 \mathrm{ml}$.

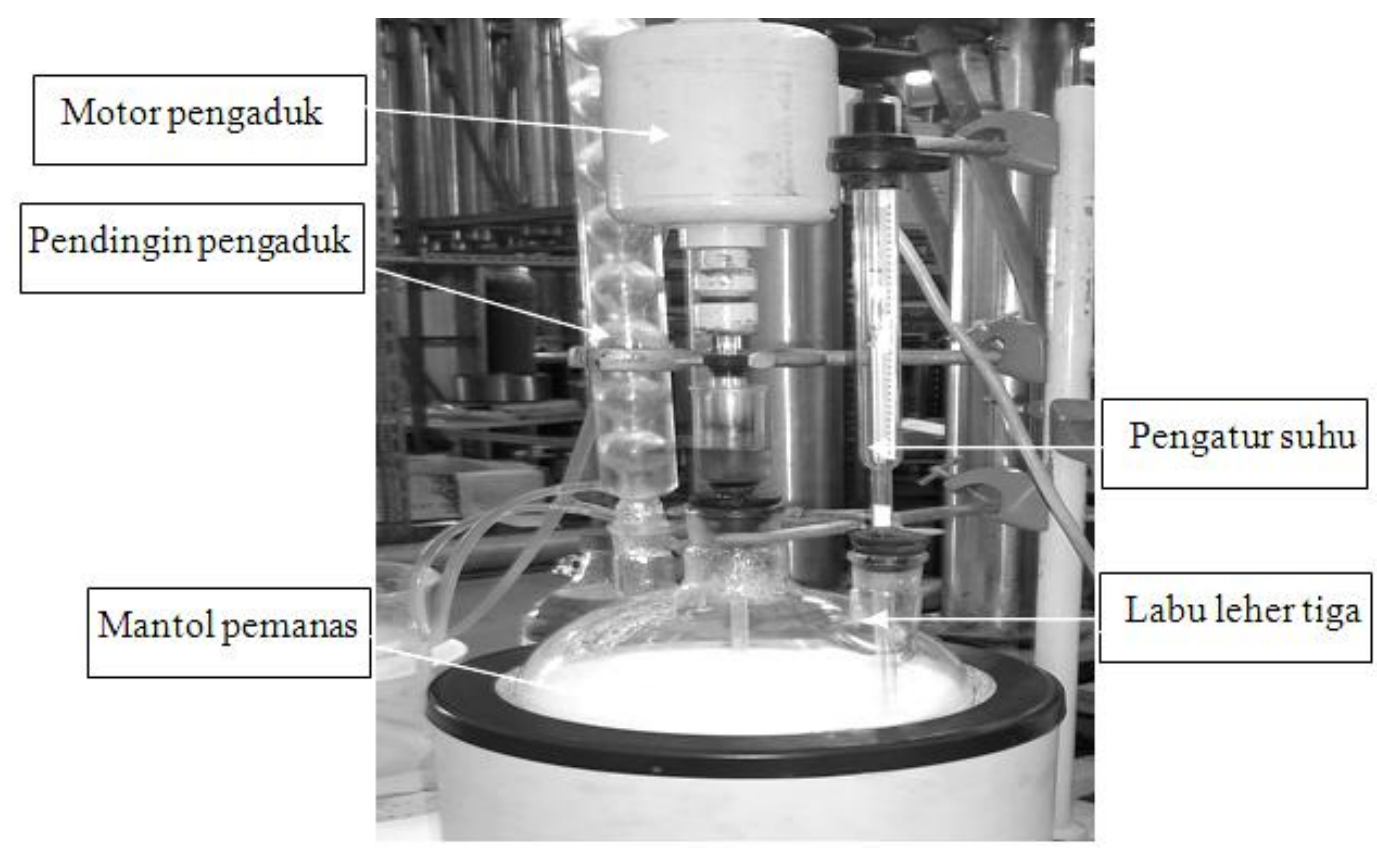

Gambar 2. Seperangkat labu untuk pembuatan ZBS

\section{Pengendapan ZBS}

Ke dalam labu leher tiga yang dilengkapi dengan reflux, pendingin, pengatur suhu dan pengaduk dimasukkan larutan ZBS, diaduk pada kecepatan 150 rpm dan dipanasi pada suhu tertentu selama waktu tertentu.

\section{Variasi $\mathrm{pH}$, konsentrasi umpan, suhu, waktu}

Variasi pH dari 1,1-2,0, variasi ini dilakukan pada saat pembuatan larutan ZBS yaitu dengan menambah $\mathrm{NH}_{4} \mathrm{OH} / \mathrm{HCl}$ ke dalam umpan sampai $\mathrm{pH}$ yang dikehendaki. Digunakan $\mathrm{pH}$ meter poket yang sebelumnya telah dikalibrasi dengan larutan standar $\mathrm{pH} 4$ dan 7.

Variasi konsentrasi umpan $(0,1-0,5 \mathrm{M})$, variasi ini dilakukan pada saat pembuatan larutan umpan ZOC dengan cara pengenceran dari larutan induk ZOC yang berkadar $72.0 \mathrm{~g} \mathrm{Zr/L}$.

Variasi suhu dari $70-100{ }^{\circ} \mathrm{C}$, variasi ini dilakukan pada saat pemanasan yaitu dengan cara mengatur suhu pada mantol pemanas sampai suhu yang ditunjukkan pada termometer stabil. Dengan cara yang sama dilakukan variasi waktu pemanasan yaitu dari 15-60 menit.

\section{Penyaringan dan Pencucian endapan}

Endapan ZBS disaring, filtrat dikumpulkan untuk dianalisis konsentrasi Zirkoniumnya dengan XRF, endapan ZBS dicuci $3 x$ dengan ABM dan keringkan.

\section{HASIL DAN PEMBAHASAN}

\section{Persiapan umpan}

Diperoleh umpan ZOC berkadar $=72.0 \mathrm{~g}$ Zr/L (analisis dengan XRF). 


\section{Variasi pH 1,1-2,0}

Umpan yang digunakan dari ZOC kristal berwarna kuning dilarutkan dalam ABM kadar Zr $=72 \mathrm{~g} / \mathrm{L}$ (analisis XRF) dijadikan 0,2 M =5,14 g Zr/L; Perbandingan $\mathrm{Zr} / \mathrm{SO}_{4}=5 / 2$; Waktu reflux =1 jam; Volume =250 $\mathrm{ml}$. Pengaruh variasi $\mathrm{pH}$ terhadap pengendapan ZBS disajikan pada gambar 3.

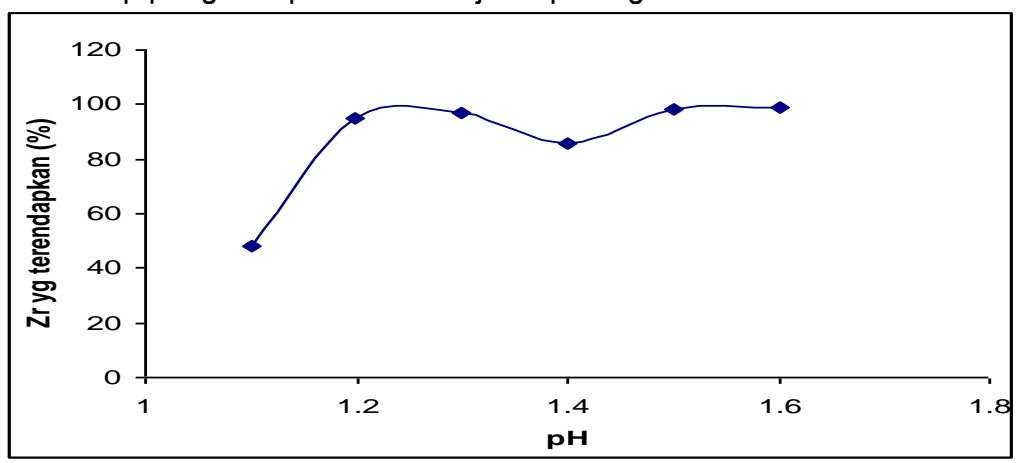

Gambar 3. Grafik hubungan antara perubahan pH dengan jumlah Zr yang terendapkan (\%) .

Variasi $\mathrm{pH}$ bertujuan untuk memisahkan Fe,Ti, U dan Th. Secara teori ZBS berwarna putih berbentuk slurry mengendap pada $\mathrm{pH}$ di bawah $2^{(16)}$. Pengamatan menunjukkan bahwa endapan ZBS berwarna putih hampir koloid (slurry). Pada $\mathrm{pH}>1,3$ larutan ZBS sudah mulai puth keruh, mungkin dikarenakan terbentuk endapan zirconium hydroxide yang mulai mengendap sekitar $\mathrm{pH}=2$ untuk $0,01 \mathrm{M}$ larutan zirkonium ${ }^{(17-18)}$. Dengan menganggap bahwa konsentrasi $\mathrm{Zr}$ yang bereaksi dengan $\mathrm{H}_{2} \mathrm{SO}_{4}$ (membentuk endapan $\mathrm{ZBS}$ ) adalah hasil pengurangan dari konsentrasi $\mathrm{Zr}$ mula-mula dikurangi konsentrasi $\mathrm{Zr}$ di setiap perubahan $\mathrm{pH}$ maka diperoleh gambar 3. Dari gambar 3 terlihat endapan ZBS pada pH 1,2, Zr yang terendapkan 94,74\%, pH optimum adalah 1,3 dengan $\mathrm{Zr}$ terendapkan $96,78 \%$. Pada $\mathrm{pH}$ optimum tersebut diharapkan $\mathrm{U}$, Th, Fe dan Ti tidak ikut mengendap dan berada dalam filtrat karena adanya sulfat, uranium mengendap sebagai $\mathrm{UO}_{2} \mathrm{SO}_{4}$ pada $\mathrm{pH}$ kurang lebih 1,03-1,6 sedangkan sebagai $\mathrm{U}\left(\mathrm{SO}_{4}\right)_{2}$ pada $\mathrm{pH}$ 0,1-1,95. Thorium mengendap sebagai $\mathrm{Th}\left(\mathrm{SO}_{4}\right)_{4}$ pada pH sekitar 2,8-5,2 dan Ti($\left(\mathrm{SO}_{4}\right)_{4}$ pada $\mathrm{pH}$ 3,55-4 dan feri/fero sulfat mengendap pada $\mathrm{pH}=8$.

\section{Variasi konsentrasi umpan}

Konsentrasi umpan ZOC divariasi dari 0,1-0,5 M; perbandingan $\mathrm{Zr} / \mathrm{SO}_{4}=5 / 2$; Waktu reflux $=1$ jam; Volume $=250 \mathrm{ml}, \mathrm{pH} 1,3$. Variasi konsentrasi umpan bertujuan untuk mendapatkan efisiensi pengendapan. Hasil pengamatan terhadap konsentrasi $\mathrm{Zr}$ dalam filtrat disetiap perubahan konsentrasi umpan ( $0,1-0,5 \mathrm{M})$ disajikan pada Gambar 4.

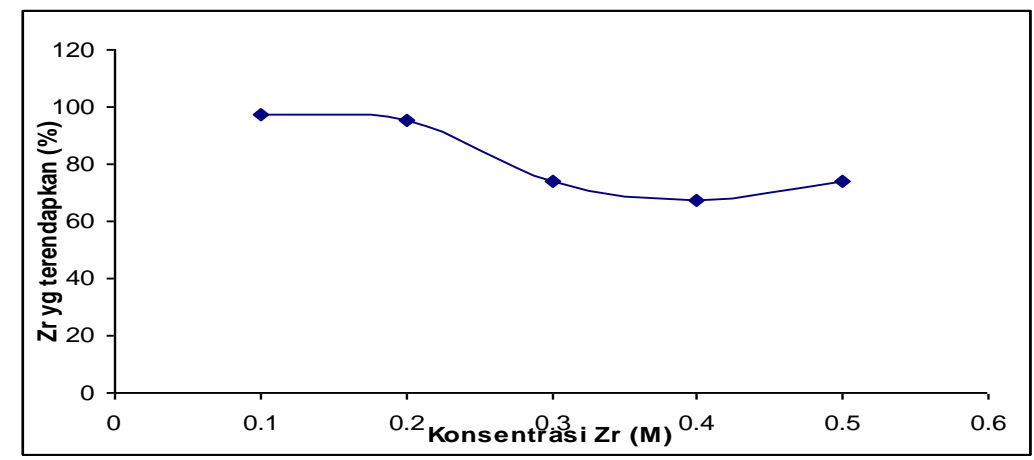

Gambar 4. Grafik hubungan antara perubahan konsentrasi umpan dengan jumlah Zr yang terendapkan (\%).

Dari gambar 4, prosentase $\mathrm{Zr}$ yang terendapkan setelah konsentrasi umpan $0,2 \mathrm{M}$ menurun dan naik lagi tetapi yang optimum pada konsentrasi 0,2 M. Pada konsentrasi umpan $=0,2 \mathrm{M}$ terjadi reaksi yang sempurna karena tumbukan antar molekul atau antar partikel lebih sempurna sehingga reaksi juga lebih sempurna dan menghasilkan konversi yang terbesar. 


\section{Variasi suhu pengendapan}

Suhu reaksi divariasi dari $70-100^{\circ} \mathrm{C}$, umpan $Z O C$ berkadar $72 \mathrm{~g} \mathrm{Zr/L}$, dijadikan $0,2 \mathrm{M}=5,14 \mathrm{~g} \mathrm{Zr/L}$; Perbandingan $\mathrm{Zr} / \mathrm{SO}_{4}=5 / 2$; Waktu reflux $=1$ jam; $\mathrm{pH}=1,3 ;$ Volume $=250 \mathrm{ml}$. Konsentrasi $\mathrm{Zr}$ dalam filtrat terhadap perubahan suhu disajikan pada Gambar 5.

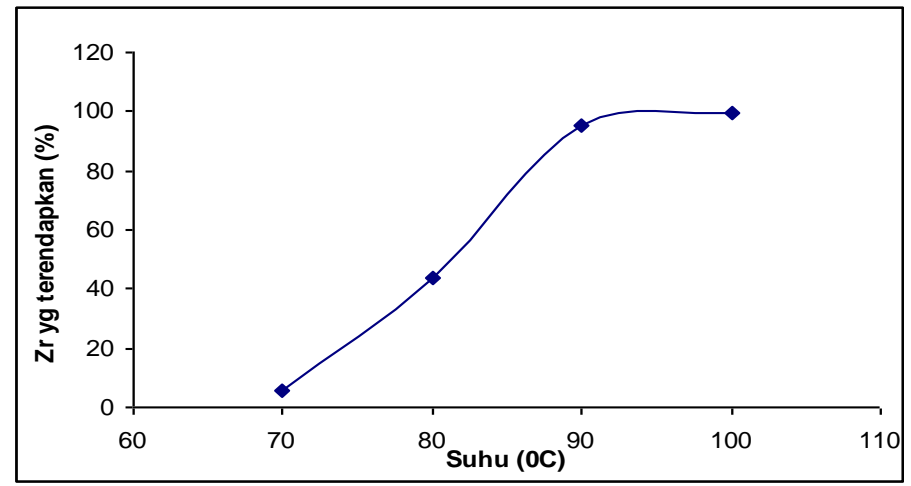

Gambar 5. Grafik hubungan antara perubahan suhu $\left({ }^{\circ} \mathrm{C}\right)$ dengan jumlah $\mathrm{Zr}$ yang terendapkan $(\%)$.

Dari gambar 5 , pada suhu $70^{\circ} \mathrm{C}$ ternyata masih sedikit sekali $\mathrm{Zr}$ yang terendapkan $(5,5 \%)$ artinya reaksi sangat dipengaruhi oleh suhu reaksi. Pada suhu $80{ }^{\circ} \mathrm{C}$ konsentrasi $\mathrm{Zr}$ yang terendapkan sudah langsung naik menjadi sekitar $50 \%$ sedang pada suhu $90{ }^{\circ} \mathrm{C}$ sudah sekitar $95 \%$. Jadi, semakin tinggi suhu reaksi semakin banyak $\mathrm{Zr}$ yang terendapkan karena tumbukan molekul semakin cepat dan banyak atau energi aktivasinya semakin tinggi dan reaksi semakin sempurna. Pada suhu sekitar $100{ }^{\circ} \mathrm{C}$ konsentrasi $\mathrm{Zr}$ yang terendapkan adalah tertinggi yaitu sekitar $99,8 \%$. Namun demikian dipilih suhu $90{ }^{\circ} \mathrm{C}$ karena membuat suhu $100^{\circ} \mathrm{C}$ sangat sulit meskipun sudah menggunakan kompor pemanas yang dilengkapi dengan direfluk.

\section{Variasi waktu pengendapan}

Waktu pengendapan divariasi dari 15-60 menit, umpan $Z O C$ kadar $Z r=72 \mathrm{~g} / \mathrm{L}$ dijadikan $0,2 \mathrm{M}=5,14 \mathrm{~g}$ $\mathrm{Zr} / \mathrm{L} ;$ Perbandingan $\mathrm{Zr} / \mathrm{SO}_{4}=5 / 2 ; \mathrm{pH}=1,3 ;$ Volume $=250 \mathrm{ml}, 90^{\circ} \mathrm{C}$. Hasil pengukuran konsentrasi $\mathrm{Zr}$ dalam filtrat terhadap perubahan waktu disajikan pada Grambar 6.

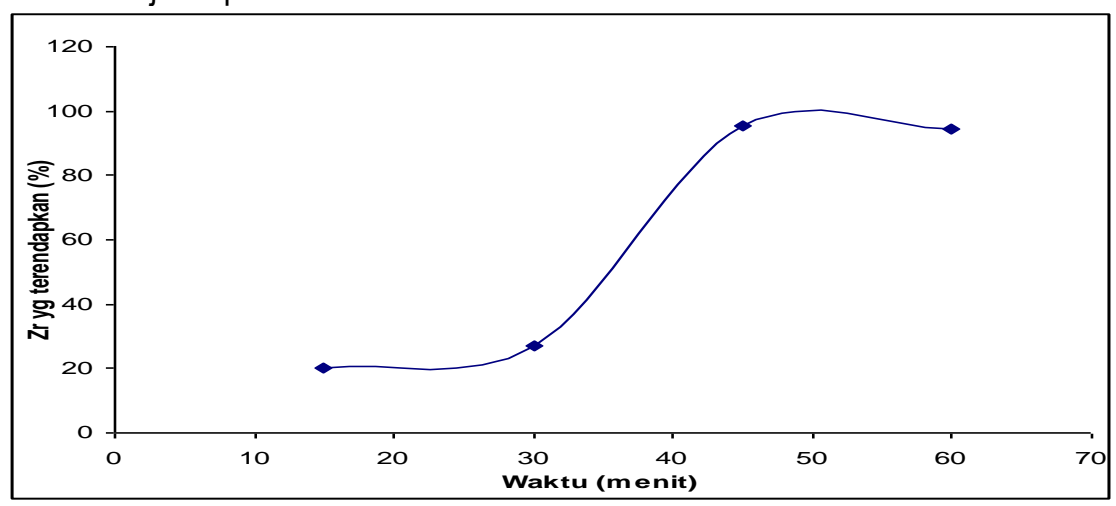

Gambar 6. Grafik hubungan antar perubahan waktu (menit) dengan jumlah Zr yang terendapkan (\%).

Dari gambar.6, .kesempurnaan reaksi sangat dipengaruhi oleh waktu yaitu pada waktu pengendapan 15-30 menit prosentase Zr yang terendapkan masih di bawah 50\%. Setelah waktu pengendapan 45-60 menit prosentase pengendapan dapat mencapai $\quad(94-95)$ \% sehingga dipilih waktu 45 menit atau lebih (1jam) agar tercapai kesempurnaan reaksi. Setelah waktu pemanasan tersebut diperkirakan waktu pemanasan tidak begitu efektif karena reaktan telah habis bereaksi. Kondisi optimum pengendapan $\mathrm{Zr}$ yang diteliti disajikan disajikan pada tabel 2.

Pada kondisi optimum (Tabel 2), selain untuk mendapatkan prosentase pengendapan $\mathrm{Zr}$ diharapkan akan mengurangi/menghilangkan pengotor $\mathrm{U}, \mathrm{Th}, \mathrm{Fe}$ dan Ti karena secara teori pengotor-pengotor tersebut tidak 
ikut mengendap dan berada dalam filtrat. Pengotor-penngotor $U, T h, F e$ dan Ti diharapkan tidak terendapkan karena uranium mengendap sebagai $\mathrm{UO}_{2} \mathrm{SO}_{4}$ pada $\mathrm{pH}$ kurang lebih 1,03-1,6 sedangkan sebagai $\mathrm{U}\left(\mathrm{SO}_{4}\right)_{2}$ pada

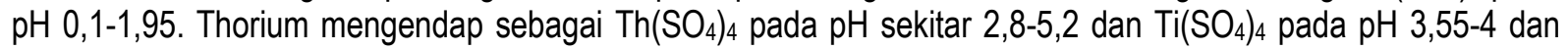
feri/fero sulafat mengendap pada $\mathrm{pH} 8$.

Tabel.2. Kondisi optimum pengendapan ZBS.

\begin{tabular}{|c|c|}
\hline Kondisi optimum & Zr terendapkan (\%) \\
\hline pH optimum $=1,3$ & 96,78 \\
Konsentrasi Umpan $=0,2 \mathrm{M}$ & 95,56 \\
Suhu $=90^{\circ} \mathrm{C}$ & 95,56 \\
Waktu $=45-60$ (menit) & $95,33-94,35$ \\
\hline
\end{tabular}

\section{KESIMPULAN}

Pengendapan ZBS dipengaruhi oleh beberapa faktor di antaranya adalah $\mathrm{pH}$, konsentrasi umpan, suhu pengendapan dan waktu. Diperoleh kondisi optimum proses pengendapan $\mathrm{ZBS}$ adalah $\mathrm{pH}=1,3$ konsentrasi umpan $=0,2 \mathrm{M}$, suhu reaksi $=90{ }^{\circ} \mathrm{C}$ dan waktu pemanasan $=45-60$ (menit) diperoleh $\mathrm{Zr}$ yang terendapkan $95,33-94,35 \%$.

\section{UCAPAN TERIMAKASIH}

Dengan terselesainya penelitian ini kami ucapkan terimakasih kepada Drs. Agus Sulistyono dan temanteman kelompok persiapan umpan zirkonium yang telah dengan tekun membuat umpan ZOC dari peleburan pasir zircon. Tak lupa juga kami ucapkan kepada Ibu Endang Nawangsih AMd dan Bapak Rohyanto yang telah dengan tekun membantu sampai terselesainya penelitian ini. Mahasiswi UNY Ratna Maysari yang telah dengan rajin membantu penelitian ini serta bapak Mulyono yang telah membantu dalam bidang analisis dengan XRF.

\section{SARAN}

Penelitian ini dilanjutkan dengan analisis kadungan U, Th, Fe dan Ti baik didalam filtrat maupun dalam hasil ZBS.

\section{DAFTAR PUSTAKA}

1. ZOLA KWELA., "The Chemistry of Zirconium", University of Pretoria etd (2006)

2. HENDRIK THEODORUSRIJNTEN, Zirconia, Drukkerij Gebr Janssen N.V, Nijmegen, (1971)

3. SOLOVKIN.A.S. and TAVETKOVA.S.V., "The Chemistry Of Aqueous Solutions Of Zirconium salt (Does The zirconyl Ion Exist)", Russian Chemical reviews 31 655, (1962)

4. NIELSEN R.H AND GOVRO R.L., "Zirconium Purification, using A Basic Sulfate Precipitation", United States Department of Inteior (1956)

5. ARAQ MANHIQUE., "Optimisation Of Alkali-Fusion Process For Zircon Sands: A Kinetic Study Of The Process," University of Pretoria etd (2003)

6. EDWADR J.PUGH., "Basic sulfate of and Methode of Making The Same", Patent, Sept. 16, (1919)

7. NGO VAN TUYEN, VU THANH QUANG, TRINH GIANG HUONG AND VUONG HUU ANH., "Preparation of High Quality Zirconium Oxychloride From Zircon of Vietnam", Institute for Technology of radioactive and Rare Element, VAEC, Vietnam, (2007)

8. NO NAME., "Experimental Design-Chemistry", Enggineering Depatrment,Preparation of Zirconia, Chapter III. Zirconium Sulfate Chemistry www.che.utah.edu/../ Amerika Serikat. Diunduh Juli 2010

9. LUO FANGCHENG, LU WENGUANG, LUO XINWEN (JIANGXI KINGAN HI TECH CO, LTD NANCHANG. Chinese Journal of Rare Metals, 01 (2003)

10.Deqing Xinkang Chemical Co.,Ltd. All Rights Reserved. Supported by ChemNet ChinaChemNet Toocle Copyright Notice, Copyright ( $\odot 2002$

11.ZHEJIANG Zr-Valley Science \& Technology Co Ltd All Rights Reserved. Supported by ChemNet ChinaChemNet Toocle Copyright Notice Copyright(C)2011 
Optimasi Kondisi Pembuatan Zirconium Basic Sulphate (ZBS) dari Zirconium Oxychloride (ZOC) (Endang Susiantini)

12. GDE PANDHE WISNU SUYANTARA," Migrasi Zirkonium dan Hafnium Pada Tumpukan Resin Anion Dalam rangka Simulasi Pemisahannya Dengan Kromatografi Anular", Thesis PascaSarjana, Universitas Gadjah Mada (2012).

13. ENDANG SUSIANTINI, M.SETYADJI, SUNARDJO," Pembuatan Spesies anion Zr-Hf-Sulfat sebagai umpan pada pemisahan Zr-Hf dengan sistem kromatografi anular kontinyu", Proseding Seminar Nasional ke-17 Teknologi dan Keselamatan PLTN Serta Fasilitas Nuklir , Yogyakarta, (2011)

14. ENDANG SUSIANTINI," Adsorpsi $\mathrm{Zr}\left(\mathrm{SO}_{4}\right)_{3} 3^{-2}$ Dalam Resin Penukar anion (DOWEX-1X8) Pada Kromatografi Anular", Proseding Pusat Teknologi Akselerator dan Proses Bahan-BATAN (2012)

15. STEPHEN LOWER, The Chem1 Virtual, www.chem1.com/acad/.../dynamics-3.html, (2011)

16. RONEMABUT, GENTLLY, YOSEPH MULLER at.all., "Method of Separation Uranium and Thorium From each other", Patent, sept, 22 (1959)

17. MOHAMMED H.AL-HAZMI, "Synthesis, Characterization, and Application of Zirconia and Sulfated Zirconia derived from Single Source", Thesis Doctor of Philosophy, King Saud University Riyadh, Saudi Arabia, May, (2005)

18. ALKANE EXPLORATION LTD.," Dubbo Zirconia Project New South Wales", Hargreave Hale Ltd and LM Associates- European Mining Conference Auatralia,.January (2005) 